\title{
Preference for Different Intensities of Red Light as Affected by the Age, Temporal Variation and Behaviour of Broiler Birds
}

\author{
D. Senaratna*, T.S. Samarakone ${ }^{1}$ and W.W.D.A. Gunawardane ${ }^{2}$
}

Postgraduate Institute of Agriculture

University of Peradeniya

Sri Lanka

\begin{abstract}
The red light (RD) marks high preference (PR), weight gain and welfare of broilers. A study was conducted to determine the PR for high (HI; 320 lux), medium (MI; 20 lux), dim (DI; 5 lux) intensities of RD and to investigate whether such PRs are influenced by age (AG), temporal variation (TV) and behaviour. The PR-chambers consisting of three identical compartments were provided with ad libitum feed, water and illumination from $5 \mathrm{~W}$ incandescent bulbs (20 lux, 20 L:4D). A randomized complete block design was used with six replicates. Five birds were initially confined to the centre of each experimental unit (24 hrs.) and then allowed to move freely. Their presence under respective light intensity (LI) was recorded with behaviour adopting scan sampling. Data were analyzed using ANOVA procedure $(\alpha=0.05)$. The $P R$ was significantly affected by $A G, T V$ and behaviour, i.e. walking [Wk] and lying [Ly]. At the week 2 (wk 2) the highest (87\%) and the lowest (3\%) PRs were marked for HI and DI, respectively, in the night (NT). Young birds (14d) preferred $H I$ to DI, and the opposite was recorded with $A G$ advancement. Irrespective of the $A G$, the highest $P R$ was recorded for DI in the morning $(M N)$ and $H I$ in the NT. The reason could be that low intensities are associated with the cooling effect. The $L I^{*} T V^{*} A G$ significantly affected on Ly and Wk. The highest Wk $(87.29 \% \pm 0.05)$ was observed in the NT under HI at wk 2 and the highest Ly $(39.95 \% \pm 0.08)$ was performed in the evening in DI at wk4. At the wk 2, all activities occurred mostly in HI; whereas at wk 5, Ly and sleeping (Sl) were dominant in DI. It is concluded that PR for different intensities of RD varies with AG advancement, temporal variation of the day, and certain behaviours (mainly Wk and Ly) of broiler birds. Older birds were inactive and preferred to perform Ly and Sl under DI.
\end{abstract}

Keywords: Behaviour, broiler birds, intensity, preference, red light.

\section{INTRODUCTION}

Light Intensity is an important aspect of artificial light for poultry production and welfare. Broilers have preferences for different light environments, especially for light colours and intensities (Savory \& Duncan 1982/83; Appleby et al., 1984; Alsam \& Wathes, 1991; Widowski et al., 1992 and Davis et al., 1999). Literature revealed that red light is more preferred by broilers especially in the night compared to green, blue and white (Senaratna et al., 2010, Senaratna et al., 2012), and providing red light during early stages has beneficial effects on higher weight gain (Woodward et al., 1969, Atapattu et al., 2007, and Senaratna et

\footnotetext{
Department of Animal Science, Faculty of Agriculture, University of Peradeniya, Sri Lanka

Department of Animal Science, Faculty of Agriculture, University of Ruhuna, Kamburupitiya, Sri Lanka

Corresponding author: dulcysenaratna@gmail.com
} 
al., 2011). Further, it has been reported that there is less cannibalism among laying hens under red light than green or white light (Bowlby, 1957; Schumaier et al., 1968), presumably because the birds cannot see the blood stimulant under red light.

There are many potential welfare benefits of improving activity of broiler chicken. Increased movements may improve bone development, litter condition and prevent skin lesions on the hocks, feet and breast, normally caused by prolonged sitting on poor quality litter (Ekstrand et al., 1997; Bizeray et al., 2002). Several studies have focused upon ways of increasing activity. Rearing broilers in bright red light early in life increased activity and decreased leg disorders compared to rearing in dim intensity blue light as found by Prayitno et al., (1997). Improperly measured light intensities may affect health, production or welfare of the flock due to the unnatural modifications of light-induced biological mechanisms. Despite those observations, the use of dim intensity for commercially housed broilers is common. However, the red light plays an important role in broiler production and welfare and must be included to the management plans after analyzing the effects of different intensities.

In order to prepare management guidelines, preference for different intensities of red light must be considered in terms of welfare. It was hypothesized that broilers have preference for a particular intensity of red light at different growth stages. The aim of this experiment was to determine what preference broilers show among a range of intensities of red light; high (HI), medium (MI) and dim (DI), and whether such preferences are influenced by age (AG), temporal variation (TV) or day session (morning vs. evening vs. night) and behavior.

\section{MATERIALS AND METHODS}

\section{Experimental birds and management}

A total of 30 broilers (strain Cobb) were subjected for the investigation. Day-old chicks were obtained from a local hatchery and were brooded under common brooding light $(60 \mathrm{~W}$, Osram incandescent bulbs). Lighting was continuous at 60 lux for the brooding period (first 7 days) and then changed to a 20L: 4D schedule at 320, 20 and 5 lux intensities as treatments during growing period. Light intensity was adjusted by using dimmer switches. The arrangement in the experimental setup was designed to give the birds an equal experience of each light intensity. Intensities were measured by angling the cosine-corrected photoreceptor sensor of a light meter (Macam Photometer, Model L 103; Macam Photometrics Ltd, Livingston, UK) in the direction of maximum radiance; a method defined by Tucker \& Charles (1993). All intensities were taken at $25 \mathrm{~cm}$ above the litter at bird's eye level.

\section{Preference testing, experimental design and protocol}

The experiment was conducted in a preference chamber, as described by Jones (1996). The chamber consisted of three identical, interconnecting compartments arranged in an annulus, and connected forming a triangular central passage. Each compartment was rectangular in shape, with a floor area of $3 \times 2 \mathrm{ft}^{2}$ and access to the adjacent compartments through an opening measuring 2'x3'(width $x$ height) in the end walls (Fig.1). Each compartment was provided with a feeder and a bell shaped drinker containing ad libitum feeds and water. Paddy husk was used as the litter material. Illumination was provided from $5 \mathrm{~W}$ incandescent red light bulbs located at the center of the each compartment and adjusted the height $1 \mathrm{ft}$ above the floor. The light bulbs for each compartment were connected to a separate dimmer 
switch set to provide the high (HI), medium (MI) and dim (DI) intensities with 320, 20 and 5 lux intensities, respectively. The variation in light intensity within each compartment was $\pm 3 \%$ of the mean, as recorded from 10 measurements taken $25 \mathrm{~cm}$ above the litter. Light intensity in each compartment was measured every $24 \mathrm{hrs}$. Allocation of the three intensities among compartments was random. Compartments were well ventilated with fresh natural air and the ambient temperature varied between 22.5 and $27.5{ }^{\circ} \mathrm{C}$ over the period of the experiment. Increasing the light intensity from minimum (5 lux) to maximum (320 lux) was found to increase ambient temperature by between 0.3 to $0.8{ }^{\circ} \mathrm{C}$. Given the adequate ventilation through the compartments, the temperature of the compartments would not have been greatly affected by either the occupancy or non-occupancy by the birds.

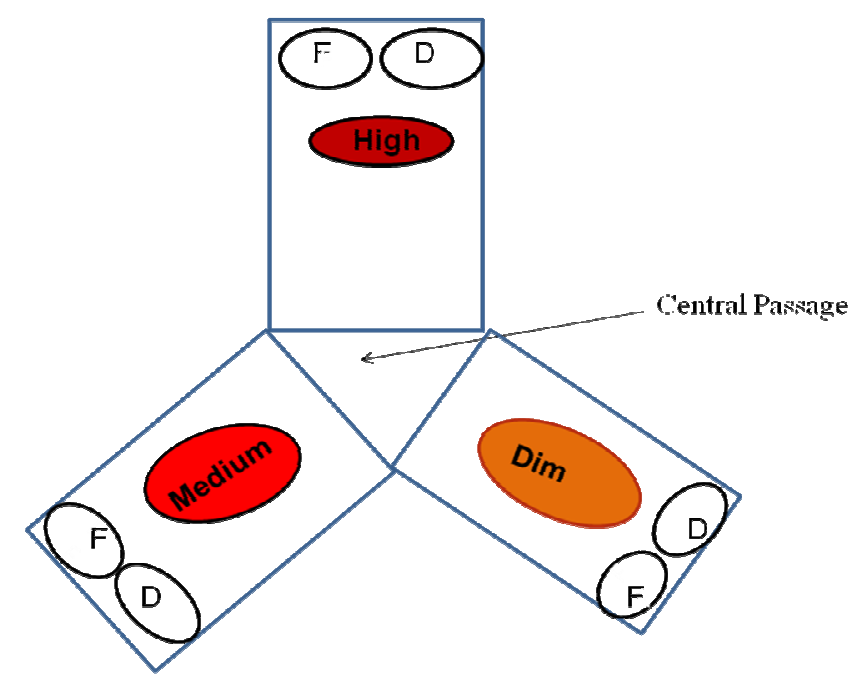

Fig. 1. Top view of the preference chamber used to test preference for high (320lux), medium (20lux) and dim (5lux) intensities of red light.

(F) -Feeder and (D) - Drinker

Five birds at the age of 8 days were randomly selected from the flock and marked them with a non toxic ink at different places of the body for individual identification. They were confined in the central triangular passage for 24 hours with a wire mesh (5 birds/ experimental unit) allowing birds to get equally familiarized to different intensities of red light before testing the preference. After 24 hours of habituation, the feeder, drinker and the wire mesh were removed. Then birds were allowed to move freely according to their preference for the red light intensities. Preference was tested in each week, over 4 consecutive weeks covering starter and finisher stages. Artificial light was provided for 20 hrs (from 2200hrs. to 0600hrs. of the following day) with a dark period (from 1800hrs. to $2200 \mathrm{hrs}$.). Simultaneously, the presence and behavior of birds under respective light intensity were recorded at every 15 min. for 3 consecutive hours during MN (0800-1100 hrs.), EV (1400-1700hrs.) and NT (2200-0100hrs). Four visits/hour/experimental units were made using scan sampling method (Martin \& Bateson, 1993). Behaviour of the birds under different light intensities was studied according to 22 , broad mutually exclusive categories using an ethogarm (Table 1). 
Table 1. Description of behavior categories used during the experiment

\begin{tabular}{|c|c|c|}
\hline & Activity & Description \\
\hline 1. & Standing & $\begin{array}{l}\text { The abdomen is not touching the litter and the bird is } \\
\text { motionless with no apparent movement of legs }\end{array}$ \\
\hline 2. & Walking & Moving forward taking one or more steps \\
\hline 3. & Lying & Head rested on something (litter or another bird) while sitting \\
\hline 4. & Eating & $\begin{array}{l}\text { Head extended towards available feed resources while beak in } \\
\text { or above the feeder appears to be manipulating or ingesting } \\
\text { feed }\end{array}$ \\
\hline 5 . & $\begin{array}{l}\text { Head } \\
\text { movement }\end{array}$ & $\begin{array}{l}\text { Immobile body apart from rapid head movements in any } \\
\text { directions or rotations of the head around its vertical or } \\
\text { horizontal axis }\end{array}$ \\
\hline 6. & Wing Flapping & $\begin{array}{l}\text { Extending both wings out from the body simultaneously and } \\
\text { flapping of wings }\end{array}$ \\
\hline 7. & $\begin{array}{l}\text { Scratching } \\
\text { floor }\end{array}$ & Scratch floor with feet usually associated with eating behaviour \\
\hline 8. & Dozing & $\begin{array}{l}\text { The head motionless and the eyes either half closed or slowly } \\
\text { opening and closing while bird is sitting }\end{array}$ \\
\hline 9. & Sleeping & $\begin{array}{l}\text { Bird's neck is fully recumbent and the eyes permanently closed } \\
\text { while lying }\end{array}$ \\
\hline 10. & $\begin{array}{l}\text { Bird } \\
\text { Interactions }\end{array}$ & $\begin{array}{l}\text { Frontal displays with raised hackles towards another bird, head } \\
\text { pecking, jumping or kicking at another bird and attacking the } \\
\text { other birds in an aggressive manner }\end{array}$ \\
\hline 11. & Dust bathing & $\begin{array}{l}\text { Bathing the dust with the use of wings, head, neck and legs } \\
\text { performing vertical wing-shaking }\end{array}$ \\
\hline 12. & Body Shaking & Raise feathers and shake body \\
\hline 13. & Drinking & $\begin{array}{l}\text { Beak in contact with water in or above the drinker and appears } \\
\text { to be drinking water }\end{array}$ \\
\hline 14. & Vocalization & Making any kind of noise \\
\hline 15. & $\begin{array}{l}\text { Preening via. } \\
\text { lying }\end{array}$ & $\begin{array}{l}\text { Beak related behaviour that beak touches the plumage of the } \\
\text { bird itself while lying }\end{array}$ \\
\hline 16. & $\begin{array}{l}\text { Preening via. } \\
\text { standing }\end{array}$ & $\begin{array}{l}\text { Beak related behaviour that beak touches the plumage of the } \\
\text { bird itself while standing }\end{array}$ \\
\hline 17. & Flying & $\begin{array}{l}\text { Flapping of the wings forcing the birds to lift from the ground } \\
\text { or displacement }\end{array}$ \\
\hline 18. & Litter Eating & Pecking in the litter and ingesting litter materials \\
\hline 19. & $\begin{array}{l}\text { Wing/ leg } \\
\text { stretching }\end{array}$ & Extending one wing and one leg at the same side of the body \\
\hline 20. & Idling & Lack of motion showing isolation from the flock \\
\hline 21. & Excretion & Expelling a semi-solid material through the anus \\
\hline 22. & Other & All other behaviours observed \\
\hline
\end{tabular}

Randomize complete block design was used with 6 replicates. During $2^{\text {nd }}$ week, day 8 was used for the conditioning and from day 9 to day 12 , preference was tested. Subsequently $2^{\text {nd }}$, $3^{\text {rd }}, 5^{\text {th }}$ and $6^{\text {th }}$ days of each week were used for testing the preference. In the remaining day 
of each week, feeders and drinkers were refilled in addition to rechecking light intensities. Bulbs were cleaned with a cotton piece of cloth to avoid dust buildup.

\section{Data recording}

From each 15 minutes of recording, one instantaneous observation ('on the dot'; Slater [1974]) was made of every bird, its presence under respective light intensity and its behavior in each compartment. These data were summed over the whole week (30 birds X 9 hrs day $^{-1}$ $\mathrm{X} 4$ days $\mathrm{X} 4$ observations $\mathrm{h}^{-1}$ ) to give estimates of the total time (\%) spent in a particular light intensity and the behavior (\%) of the birds, in each compartment.

\section{Statistical analysis}

The data were analyzed by General Linear Model in the Statistical Analysis Software (SAS, SAS Institute Inc. Release 9.1.3), for the effects of light intensity (HI, MI, DI) and its interaction with age ( 2 vs. 3 vs. 4 vs 5 weeks) and variation of the day (MN vs. EV vs. NT). Duncan's Mean Test was used for the mean separation. Percentage data was $(\log +1)$ transformed prior to analysis to normalize distribution. Least significant difference value was calculated for the presence and all the significantly different $(\mathrm{p}<0.05)$ behaviours of birds.

\section{RESULTS AND DISCUSSION}

\section{Total occupancy/preference}

Results indicate that chicks of commercial broiler strain Cobb showed significant preference when they are allowed to choose among a range of intensities of red light. At week 2, the highest $(87 \%)$ preference was marked for $\mathrm{HI}$ in the night and the lowest $(3 \%)$ was marked for DI also in the night (Fig. 2).

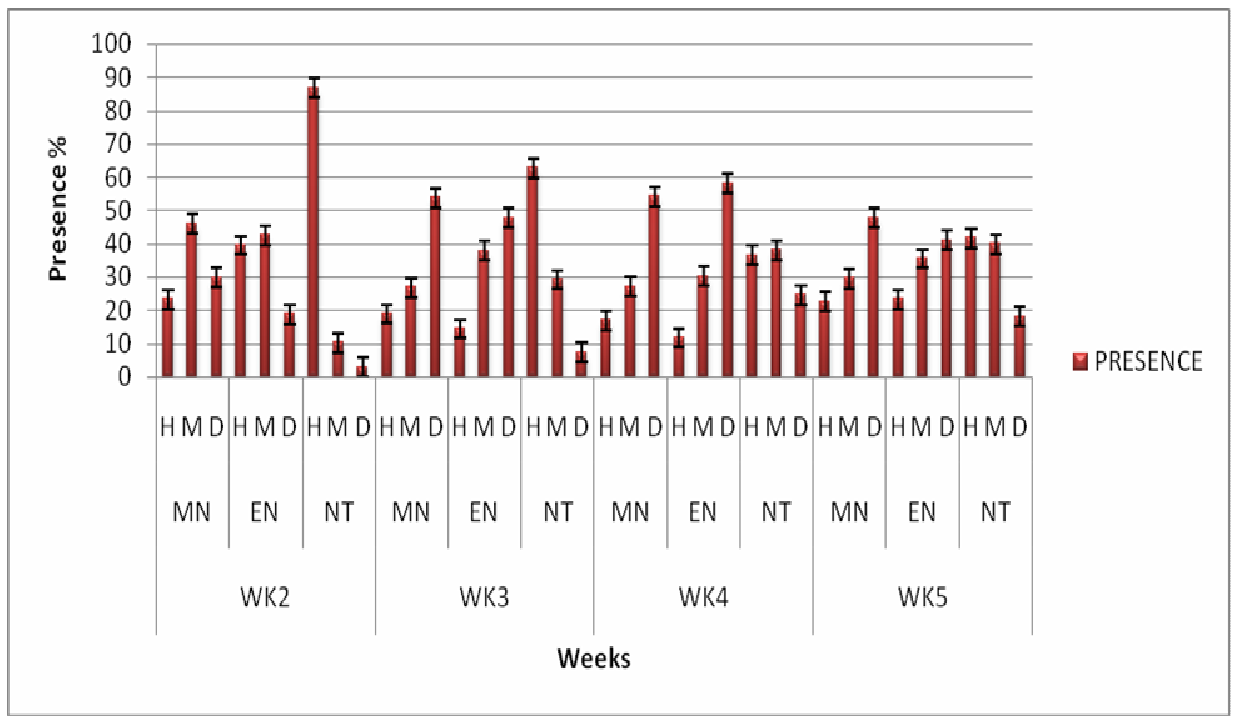

Fig. 2. Presence of birds (\%) at different intensities of RD at different sessions of the day and ages

MN-Morning, EN-Evening, NT-Night

H-High Intensity , M-Medium Intensity, D-Dim Intensity 
Preference was significantly affected by the age and the temporal variation of the day. Thus, 2 weeks old birds spent the highest time (\%) in the brightest light (320 lux) and least time in the dimmest light (5 lux) specially in the night, whereas the opposite trend was recorded with age advances (overall mean). After week 4 again preference for HI increased while decreasing the preference for DI, but still marking the highest for DI. Almost similar preference was shown for MI ( $>0.05)$ at week 5 (Fig. 3). This finding is in accordance with the Davis et al., 1999 who found that the highest preference for the brightest light (200 lux) and least preference for 6 lux recorded at the early stage of the life. Further, birds at 6 weeks in their experiment marked the opposite. MI always showed intermediate results.

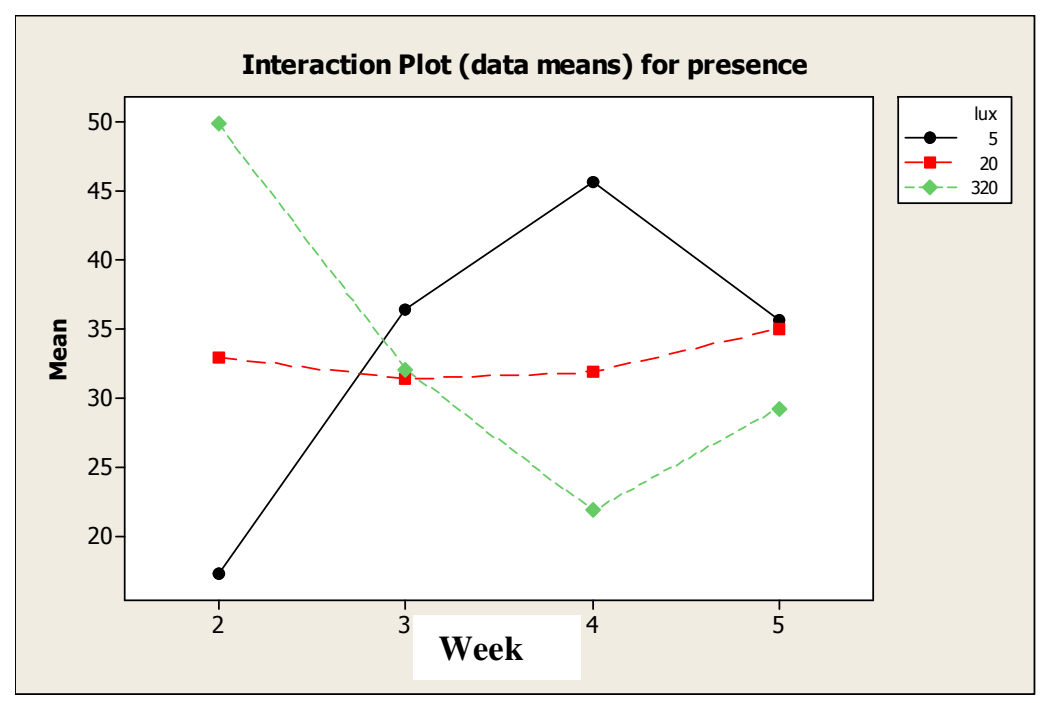

Fig. 3. Effect of age (weeks) on time spent (\%) in a particular light intensity for 2, 3, 4 and 5 weeks age categories

There was a significant $(\mathrm{p}<0.05)$ effect of age*light intensity and temporal variation*light intensity interactions on the preference of birds. Irrespective of the age, the highest preference was recorded for DI in the morning while HI was most preferred in the night (Fig. 4). Broilers might have preferred DI during day time as part of light received by sun light. Also low intensities associated with comparatively a cooling effect may be the reason to prefer DI during day time and vise versa for the night. Therefore, temporal variation of the day is also a factor that determines the preference for different intensities of red light. 


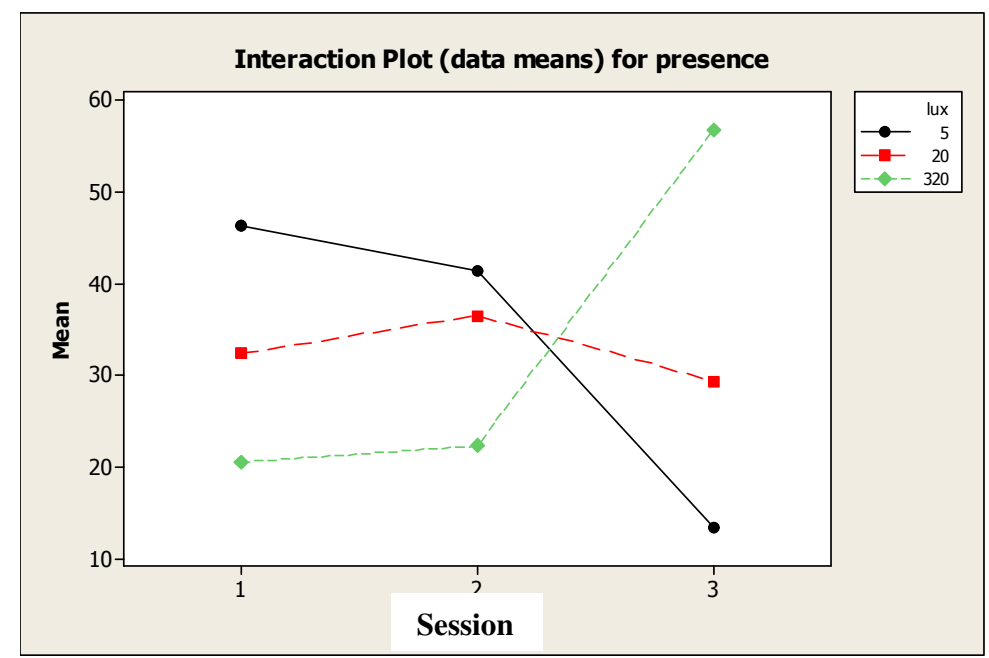

Fig. 4. Effect of the temporal variation (1-morning, 2-evening, 3-night) on time spent (mean \%) on a particular light intensity.

\section{Behaviour of broilers in the red light intensity environment}

There was a significant three factor interaction effect (light intensity*temporal variation*age) on two behaviours; lying and walking (Table 2). Lying, drinking, sleeping, dozing and dust bathing were significantly affected by the light intensity. Certain behaviours depend on the age except for eating, bird interaction, dozing, wing/leg stretching, scratching floor, body shaking and others. The apparent reversal of overall preference in the present experiment was mainly due to changes associated with the most common and frequent two activities i.e. walking and lying (Table 3 and 4). 
Table 2. Level of significance of the effect of different intensities of red light, Age (AG), Temporal Variation (TV) and their interactions on behaviour

\begin{tabular}{|c|c|c|c|c|c|c|c|}
\hline Behaviour & (LI) & $(\mathrm{TV})$ & $(\mathrm{AG})$ & LI*TV & $\mathrm{LI} * \mathrm{AG}$ & $\mathrm{LI}^{*} \mathrm{TV} * \mathrm{AG}$ & $E M S^{*}$ \\
\hline Lying & $* * *$ & $* * *$ & $* * *$ & $* * *$ & $* * *$ & $* * *$ & 52.25 \\
\hline Standing & NS & NS & $* * *$ & $* * *$ & $* * *$ & NS & 2.53 \\
\hline Eating & NS & $* * *$ & NS & $* * *$ & NS & NS & 5.23 \\
\hline Litter eating & NS & $* * *$ & $* * *$ & NS & NS & NS & 0.96 \\
\hline Walking & NS & NS & $* * *$ & $* * *$ & NS & $* * *$ & 1.05 \\
\hline Drinking & $* * *$ & NS & $* * *$ & $* * *$ & $* * *$ & NS & 14.78 \\
\hline $\begin{array}{l}\text { Wing } \\
\text { flapping }\end{array}$ & NS & NS & $* *$ & $* *$ & NS & NS & 0.10 \\
\hline Running & NS & NS & $* * *$ & NS & NS & NS & 0.05 \\
\hline $\begin{array}{l}\text { Bird } \\
\text { Interaction }\end{array}$ & NS & $* * *$ & NS & NS & $* *$ & NS & 0.07 \\
\hline Sleeping & $* *$ & $* * *$ & $* * *$ & $* * *$ & $* * *$ & NS & 9.87 \\
\hline Dozing & $* *$ & $* * *$ & NS & $* * *$ & $* * *$ & NS & 1.63 \\
\hline $\begin{array}{l}\text { Wing Leg } \\
\text { Stretching }\end{array}$ & NS & NS & NS & $* * *$ & NS & NS & 0.29 \\
\hline Preening & NS & NS & $* *$ & $* * *$ & $* * *$ & NS & 2.306 \\
\hline Dust Bathing & $* * *$ & $* * *$ & $* * *$ & $* *$ & $* * *$ & NS & 0.37 \\
\hline Vocalization & NS & $* *$ & $* * *$ & NS & NS & NS & 0.05 \\
\hline $\begin{array}{l}\text { Scratching } \\
\text { Floor }\end{array}$ & NS & $* *$ & NS & NS & NS & NS & 0.02 \\
\hline $\begin{array}{l}\text { Body } \\
\text { Shaking }\end{array}$ & N/A & N/A & N/A & N/A & N/A & NS & 0.00 \\
\hline Other & NS & $\mathrm{NS}$ & $\mathrm{NS}$ & $\mathrm{NS}$ & NS & $\mathrm{NS}$ & 0.04 \\
\hline
\end{tabular}

$* * \mathrm{p}<0.01, * * * \mathrm{p}<0.001, \mathrm{NS}-$ not significant $(\mathrm{p}>0.05) ; \mathrm{N} / \mathrm{A}-$ not applicable, EMS ${ }^{*}$-Error Mean Square

The highest $(\mathrm{P}<0.05)$ walking bahaviour was shown under HI during week 2 in the night. At the same age, the lowest walking behaviour was observed under DI (Table 3). This shows that the birds were seemed more active under HI and vise versa under DI light environments (Table 3 and 4). 
Table 3. Variation of walking behavior (\% time) of birds in different age categories according to the temporal variation of the day under different light Intensities.

\begin{tabular}{|c|c|c|c|c|c|}
\hline Age & $\begin{array}{l}\text { Temporal } \\
\text { variation }\end{array}$ & $\begin{array}{l}\text { Dim Intensity } \\
(5 \operatorname{lux})\end{array}$ & $\begin{array}{l}\text { Medium } \\
\text { Intensity } \\
(20 \text { lux })\end{array}$ & $\begin{array}{l}\text { High Intensity } \\
\text { (320 lux) }\end{array}$ & $\begin{array}{ll}\text { LSD } & \text { at } \\
0.05 & \\
\text { level } & \end{array}$ \\
\hline $\begin{array}{l}7-14 d \\
(w k 2)\end{array}$ & $\begin{array}{l}\mathrm{MN} \\
\mathrm{EN} \\
\mathrm{NT}\end{array}$ & $\begin{array}{l}27.25^{\mathrm{a}} \pm 0.3 \\
18.02^{\mathrm{b}} \pm 0.2 \\
2.763^{\mathrm{c}} \pm 0.4\end{array}$ & $\begin{array}{l}43.10^{\mathrm{a}} \pm 0.2 \\
32.32^{\mathrm{b}} \pm 0.4 \\
6.882^{\mathrm{c}} \pm 0.5\end{array}$ & $\begin{array}{l}21.38^{\mathrm{a}} \pm 0.4 \\
26.12^{\mathrm{b}} \pm 0.6 \\
87.29^{\mathrm{c}} \pm 0.1\end{array}$ & \\
\hline $\begin{array}{l}14-21 d \\
(w k 3)\end{array}$ & $\begin{array}{l}\text { MN } \\
\text { EN } \\
\text { NT }\end{array}$ & $\begin{array}{r}51.77^{\mathrm{a}} \pm 0.2 \\
45.73^{\mathrm{b}} \pm 0.2 \\
6.33^{\mathrm{c}} \pm 0.4\end{array}$ & $\begin{array}{l}22.42^{\mathrm{a}} \pm 0.3 \\
37.09^{\mathrm{b}} \pm 0.2 \\
29.05^{\mathrm{c}} \pm 0.1\end{array}$ & $\begin{array}{l}17.48^{\mathrm{a}} \pm 0.3 \\
13.06^{\mathrm{b}} \pm 0.3 \\
63.29^{\mathrm{c}} \pm 0.1\end{array}$ & \\
\hline $\begin{array}{l}22-28 d \\
(w k 4)\end{array}$ & $\begin{array}{l}\text { MN } \\
\text { EN } \\
\text { NT }\end{array}$ & $\begin{array}{l}55.03^{\mathrm{a}} \pm 0.0 \\
58.03^{\mathrm{b}} \pm 0.1 \\
23.17^{\mathrm{c}} \pm 0.2\end{array}$ & $\begin{array}{l}27.39^{\mathrm{a}} \pm 0.1 \\
29.84^{\mathrm{b}} \pm 0.2 \\
37.69^{\mathrm{c}} \pm 0.1\end{array}$ & $\begin{array}{l}16.83^{\mathrm{a}} \pm 0.2 \\
12.48^{\mathrm{b}} \pm 0.1 \\
36.25^{\mathrm{c}} \pm 0.1\end{array}$ & 0.229 \\
\hline $\begin{array}{l}29-35 d \\
\text { (wk5) }\end{array}$ & $\begin{array}{l}\text { MN } \\
\text { EN } \\
\text { NT }\end{array}$ & $\begin{array}{l}46.6^{\mathrm{a}} \pm 0.2 \\
40.35^{\mathrm{b}} \pm 0.1 \\
17.61^{\mathrm{c}} \pm 0.2\end{array}$ & $\begin{array}{l}29.29^{\mathrm{a}} \pm 0.1 \\
35.82^{\mathrm{b}} \pm 0.1 \\
37.69^{\mathrm{c}} \pm 0.1\end{array}$ & $\begin{array}{l}40.54^{\mathrm{a}} \pm 0.1 \\
22.81^{\mathrm{b}} \pm 0.2 \\
42.31^{\mathrm{c}} \pm 0.1\end{array}$ & \\
\hline
\end{tabular}

a,b,c Means within a row followed by different superscripts within the column for each temporal variation are significantly different $(\mathrm{P}<0.05)$.

It was also observed that eating, drinking and litter eating behavioural activities were more under HI than under DI at all ages and day sessions. However, these trends were less marked towards the latter part of the life, during week 4 and week 5. Irrespective of the age, lying behaviour increased from the dimmest to the brightest, especially during night while walking behavior also increased again during night indicating that the birds who are engaged in walking used to do more lying to get relaxed.

Irrespective of the age, birds under DI showed comparatively a high lying behaviour during day time. Davis et al. (1999) found that the time spent on resting/lying increased from DI to bright light at week 2, and decreased from the dimmest to brightest at week 6 . The present findings agree with those reported by Davis et al. (1999), and further the present results revealed the same trend for the whole growing period of birds.

It was also observed that during week 2 all behavioural activities occurred mostly in HI, whereas during week 5 lying and sleeping were the main behavioural activities under DI and other activities performed mainly under HI. This raises the question whether the birds entered a particular light environment in order to perform a particular activity or whether the light intensity influenced the type of behavior shown by them. 
Table 4. Variation of lying behavior (\% time) of birds in different age categories according to the temporal variation of the day under different light Intensities.

\begin{tabular}{|c|c|c|c|c|c|c|}
\hline Age & Session & $\begin{array}{l}\text { Dim } \\
\text { Intensity } \\
(5 \text { lux })\end{array}$ & $\begin{array}{l}\text { Medium } \\
\text { Intensity }\end{array}$ & $\begin{array}{l}\text { High } \\
\text { Intensity }\end{array}$ & $\begin{array}{l}\text { LSD at } \\
\text { level }\end{array}$ & 0.05 \\
\hline $\begin{array}{l}7-14 d \\
(w k 2)\end{array}$ & $\begin{array}{l}\text { MN } \\
\text { EN } \\
\text { NT }\end{array}$ & $\begin{array}{r}12.21^{\mathrm{a}} \pm 0.2 \\
7.16^{\mathrm{b}} \pm 0.3 \\
1.60^{\mathrm{c}} \pm 0.3\end{array}$ & $\begin{array}{r}18.01^{\mathrm{a}} \pm 0.2 \\
14.98^{\mathrm{b}} \pm 0.2 \\
2.54^{\mathrm{c}} \pm 0.2\end{array}$ & $\begin{array}{r}8.71^{\mathrm{a}} \pm 0.3 \\
10.19^{\mathrm{b}} \pm 0.5 \\
28.18^{\mathrm{c}} \pm 0.2\end{array}$ & \multirow{4}{*}{0.229} & \\
\hline $\begin{array}{l}14-21 d \\
(w k 3)\end{array}$ & $\begin{array}{l}\text { MN } \\
\text { EN } \\
\text { NT }\end{array}$ & $\begin{array}{l}25.21^{\mathrm{a}} \pm 0.2 \\
27.69^{\mathrm{b}} \pm 0.2 \\
2.58^{\mathrm{c}} \pm 0.3\end{array}$ & $\begin{array}{l}10.25^{\mathrm{a}} \pm 0.3 \\
21.19^{\mathrm{b}} \pm 0.1 \\
11.75^{\mathrm{c}} \pm 0.1\end{array}$ & $\begin{array}{l}9.48^{\mathrm{a}} \pm 0.2 \\
0.83^{\mathrm{b}} \pm 0.4 \\
28.91^{\mathrm{c}} \pm 0.1\end{array}$ & & \\
\hline $\begin{array}{l}22-28 d \\
(w k 4)\end{array}$ & $\begin{array}{l}\text { MN } \\
\text { EN } \\
\text { NT }\end{array}$ & $\begin{array}{l}33.08^{\mathrm{a}} \pm 0.1 \\
39.95^{\mathrm{b}} \pm 0.1 \\
10.84^{\mathrm{c}} \pm 0.2\end{array}$ & $\begin{array}{l}16.56^{\mathrm{a}} \pm 0.1 \\
19.51^{\mathrm{b}} \pm 0.1 \\
17.72^{\mathrm{c}} \pm 0.1\end{array}$ & $\begin{array}{r}10.06^{\mathrm{a}} \pm 0.2 \\
8.02^{\mathrm{b}} \pm 0.1 \\
14.7^{\mathrm{c}} \pm 0.2\end{array}$ & & \\
\hline $\begin{array}{l}29- \\
35 d \\
(w k 5)\end{array}$ & $\begin{array}{l}\text { MN } \\
\text { EN } \\
\text { NT }\end{array}$ & $\begin{array}{r}23.32^{\mathrm{a}} \pm 0.1 \\
22.15^{\mathrm{b}} \pm 0.1 \\
6.95^{\mathrm{c}} \pm 0.2\end{array}$ & $\begin{array}{l}16.49^{\mathrm{a}} \pm 0.2 \\
21.16^{\mathrm{b}} \pm 0.3 \\
17.25^{\mathrm{c}} \pm 0.1\end{array}$ & $\begin{array}{l}13.34^{\mathrm{a}} \pm 0.1 \\
12.86^{\mathrm{b}} \pm 0.2 \\
17.21^{\mathrm{c}} \pm 0.1\end{array}$ & & \\
\hline
\end{tabular}

$\overline{a, b, c}$ Means within a row followed by different superscripts within the column for each temporal variation are significantly different $(\mathrm{P}<0.05)$.

It has been reported that both physical activity and energy expenditure of laying hens were found to be increased progressively in response to a range of increasing light intensities between 1 lux and 120 lux (Boshouwers \& Nicaise, 1987). In another comparison, growing broilers kept in brightly lit (180 lux) pens were more active than others in dimly lit (6 lux) pens (Newberry et al., 1988). The results of the present study also confirm that there is a positive relationship between light intensity and activity level within the range of intensities tested in the study. Accordingly, there are associations between reduced activities under DI and increased activity (eating, drinking, litter eating, locomotion) under HI light environments in broilers. It is assumed that in addition to a range of variations of the given light intensities, some variation in the temporal distribution of ambient light intensity, to provide both dimly (<10 lux) and brightly (>320 lux) lit environments might positively contribute to the welfare of, specially the older poultry.

\section{CONCLUSION}

Preference for different intensities of red light varies with age advancement, variation of the day and certain behaviours (mainly walking and lying). Older birds were inactive and prefer to perform lying and sleeping under dim light environment. 


\section{REFERENCES}

Alsam, H. and Wathes, C.M. (1991) Conjoint preferences of chicks for heat and light intensity. British Poultry Science, 32, 899-916.

Appleby, M.C., McRae H.E. and Pietz B.E. (1984) The effect of light on the choice of nests by domestic hens. Applied Animal Ethology, 11, 249-254.

Atapattu, N.S.B.M. and Belpagodagamage, G.D.U. (2007) The effects of colour of lighting on broiler growth performance and feed and water intake pattern. Proceedings of the first annual symposium of the faculty of Agriculture, University of Sabaragamuwa, Sri Lanka. Pp 74

Bizeray, D., Leterrier, C., Constantin, P., Le Pape, G. and Faure, J.M. (2002) Typology of activity bouts and effect of fearfulness on behaviour in meat-type chickens. Behavioural Processes 58, 45-55.

Boshouwers F. M. G. and Nicaise E. (1987) Physical activity and energy expenditure of laying hens as affected by light intensity. British Poultry Science, 33, 711-717

Bowlby, G.M.S., (1957).Some preliminary investigations into the effect of light on broilers. World's Poultry Science Journal, 13, 214-226.

Davis, N.J., Prescott, N.B., Savory, C.J. and Wathes, C.M. (1999) Preferences of growing fowls for different light intensities in relation to age, strain and behaviour. Animal Welfare 8, 193- 203.

Ekstrand, C., Algers, B. and Svedberg, J. (1997) Rearing conditions and footpad dermatitis in Swedish broiler chickens. Preventive Veterinary Medicine 31, 167-174.

Jones, R.B. (1996) Fear and adaptability in poultry: insights, implications and imperatives. World's Poultry Science Journal, 52, 131-174.

Martin, P. and Bateson, P. (1993) Measuring Behaviour: An Introductory Guide. Secnd. Editn. Cambridge University Press, Cambridge, UK.

Newberry, R.C., Hunt R.J. and Gardiner E.E. (1988) Influence of light intensity on behaviour and performance of broiler chickens. Poultry Science, 67, 1020-1025

Prayitno, D.S., Phillips C.J.C. and Omed H. (1997) The effects of colour of lighting on the behaviour and production of meat chicken. Poultry Science, 76, 452-457.

Prescott, N.B. and Wathes, C.M. (1999) Spectral sensitivity of the domestic fowl (Gallus g. domesticus). British Poultry Science, 40, 332-339.

SAS, 2003. The SAS System for Windows, Release 9.1.3 Service pack 2, TS-level 01M3.SAS Institute Inc., Cary, NC, USA.

Savory, C.J. and Duncan, I.J.H. (1982/83) Voluntary regulation of lighting by domestic fowl in Skinner boxes. Applied Animal Behaviour Science, 64, 47-55. 
Schumaier, G., P.C. Harrison and J.McGinnis, (1968) The effects of colored fluorescent light on growth, cannibalism and subsequent egg production of single comb White Leghornpullts. Poultry Sci. 47, 1599-1602.

Senaratna, S., Samarakone, T., Atapattu, N.S.B.M., Paranawithana, D.R. and Chandrasiri, W.C.J. (2010) Light colour preference in broilers reared in tropical environment. Proc. $7^{\text {th }}$ Academic Sessions, University of Ruhuna. (p 114)

Senaratna, D, Samarakone, T., Madusanka, A.A.P. and Gunawardane, W.W.D.A (2012) Preference of Broiler Chicken for Different Light Colours In Relation to Age, Session of the Day and Behaviour. J. Tropical Agricultural Research, 23, 193-203.

Senaratna, D, Samarakone, T., Madusanka, A.A.P. and Gunawardane, W.W.D.A (2011b) Performance, behaviour and Welfare Aspects of Broilers as affected by Different Colours of Artificial Light, Tropical Agricultural Research and Extension, 14(2), 38-44.

Slater, P.J.B. (1974) Data Collection. In P.W.Colgan (Ed.), Quantitative Ethology, (pp 7-24) New York; Wiley.

Tucker, S.S. and Charles D.R. (1993) Light intensity, intermittent lighting and feeding regime during rearing as affecting egg production and egg quality. British Poultry Science, $34,255-266$.

Widowski, T.M., Keeling, L.J. and Duncan, I.J.H. (1992) The preferences of hens for compact fluorescent over incandescent lighting. Canadian Journal of Animal Science, 72, 203-211.

Woodward, A.E., J.A. Moore and W.D. Wilson (1969) Effect of wavelength of light on growth and reproduction in Japanese quail (Coturnix coturnix japonica) Poultry Sci., 48, 118-123. 